\title{
Effects of reverse cold rolling on the microstructure, texture and mechanical properties of AA1100 aluminium alloys
}

\author{
O. Rivero 1 , D.R. Pico ${ }^{1}$, L.G. Castruita ${ }^{2}$, F. García-Pastor ${ }^{3}$ and J. Unfried-Silgado ${ }^{*}$ \\ 1 Universidad de Córdoba. Departamento de ingeniería mecánica. Grupo ICT. Carrera 6 No. 77- 305 ZIP:230002, Montería - Córdoba, Colombia \\ Phone: $+57(4) 7860920$ \\ 2 Universidad Autónoma de Coahuila; Facultad de Ingeniería Mecánica y Eléctrica, Av. Barranquilla S/N, Col. Guadalupe, Monclova 25750, México \\ ${ }^{3}$ CINVESTAV-IPN, Unidad Saltillo, Industria Metalúrgica 1062, Parque Industria Saltillo, Ramos Arizpe, Ramos Arizpe 25900, México
}

\begin{abstract}
In this work the microstructure, texture and mechanical properties during different stages of reverse cold rolling (RCR) process on aluminium alloy AA1100-H14 were analysed. Microstructure was observed using optical and electron scanning microscopy. Texture was analysed using X-ray diffraction (macrotexture) and electron back-scattering diffraction (microtexture) techniques. Tensile test and microhardness measurements were carried out. Results showed that a high deformation using RCR was obtained in samples of annealed state leading to maximum values of tensile strength and hardness, along with a reduction of ductility. Intensity of [-fibres decreased producing unstable textures $\{112\}<110\rangle$ while microstructure exhibited refinement of grain, with enlarged morphology.
\end{abstract}

ARTICLE HISTORY

Received: 14th Dec 2019

Revised: $21^{\text {st }}$ Sept 2020

Accepted: 222nd Oct 2020

\section{KEYWORDS}

Reverse cold rolling; aluminium alloys;

texture;

annealing;

mechanical properties

\section{INTRODUCTION}

The AA1xxx series are a group of high purity commercial aluminium alloys (with minimum content of $99 \%$-wt. Al), which have a good corrosion resistance, high thermal and electrical conductivity, and excellent conformability. Usual application for this type of alloys is the fabrication using draw operations of devices for food, chemical and electrical industry stand out [1]. These alloys have low mechanical strength, which could be eventually increased by strain hardening [2]. Rolling processes are commonly used for this purpose, aiming to obtain sheets, which are traditionally used for the manufacture of insulating coatings, sheets, and kitchen tools [3, 4].

Aluminium texture has been extensively researched aiming to improve their formability, since it allows to understand the deformation process and could be used to increase the performance of the material. Usually, plastic deformation by rolling processes, such as extrusion and embossing generate a strong texture, particularly at room temperature [5, 6]. In metal alloys with FCC structure, the texture formed during the rolling processes can usually be divided into three types: recrystallization texture, deformation texture and shear texture [6-8]. Typically, texture is measured in bulk using X-ray diffraction (XRD) and in microregions using backscattered electron diffraction (EBSD) techniques, and can be represented by orientation distribution functions (ODF's). In these measurements the orientation corresponds to a specific set of Euler angles $(\varphi 1, \varphi, \varphi 2$ in the Bunge context) [9-11]. In Table 1 the most representative texture components for aluminium alloys are listed, and their corresponding Euler angles and Miller indexes [7].

Table 1. Miller indexes and Euler angle for typical texture components in aluminum alloys

\begin{tabular}{ccccc}
\hline \multirow{2}{*}{ Notation } & Miller's indices & \multicolumn{3}{c}{ Euler angle $\left(^{\circ}\right.$ ) } \\
\cline { 2 - 5 } & $\{h k l\}<u v w>$ & $\varphi_{1}$ & $\Phi$ & $\varphi_{2}$ \\
\hline Cube & $\{100\}<100>$ & 0 & 0 & 0 \\
P & $\{011\}<122>$ & 70 & 45 & $0 / 90$ \\
Q & $\{013\}<231>$ & 59 & 37 & 63 \\
Brass & $\{110\}<112>$ & 35 & 45 & 0 \\
Cupper & $\{112\}<111>$ & 90 & 35 & 45 \\
Goss & $\{110\}<001>$ & 0 & 45 & 0 \\
S & $\{123\}<634>$ & 59 & 37 & 63 \\
\hline
\end{tabular}


Table 1. Miller indexes and Euler angle for typical texture components in aluminum alloys (cont.)

\begin{tabular}{ccccc}
\hline \multirow{2}{*}{ Notation } & Miller's indices & \multicolumn{3}{c}{ Euler angle $\left(^{\circ}\right)$} \\
\cline { 2 - 5 } & $\{h k l\}<u v w>$ & $\varphi_{1}$ & $\Phi$ & $\varphi_{2}$ \\
\hline R-cub & $\{100\}<110>$ & 45 & 0 & 0 \\
E & $\{111\}<110>$ & $0 / 60$ & 55 & 45 \\
F & $\{111\}<112>$ & $30 / 90$ & 55 & 45 \\
$\alpha$-fiber & $<011>\| N D$ & $0-90$ & 45 & 0 \\
$\beta$-fiber & - & $90 / 35$ & $35 / 45$ & $45 / 90$ \\
$\gamma$-fiber & $<111>\| N D$ & $60-90$ & 54.7 & 45 \\
$\theta$-fiber & $<100>\| N D$ & $0-90$ & 0 & 45 \\
\hline
\end{tabular}

During cold rolling, crystallographic orientations of the aluminium alloys are forced to preferential orientations according to the plastic flow direction, thus establishing the so-called deformation textures [12]. Final deformation texture depends mainly on initial grain orientation and both rolling process parameters and direction [13].

Reverse cold rolling (RCR) process is performed by alternating the rolling direction $180^{\circ}$ and turning the face between each rolled pass, as shown in Figure 1a. Unlike to conventional rolling process, this process improves intensity of shear deformation through the entire thickness of the sheet, enhancing the deformation behaviour. Due to application of this process, shear texture components $\{001\}\langle 110\rangle,\{111\}\langle 110\rangle$ and $\{111\}\langle 112\rangle$ can be obtained [14]. However, it is possible to obtain a gradient of texture throughout the thickness of the sheet, which could modify the draw process properties.
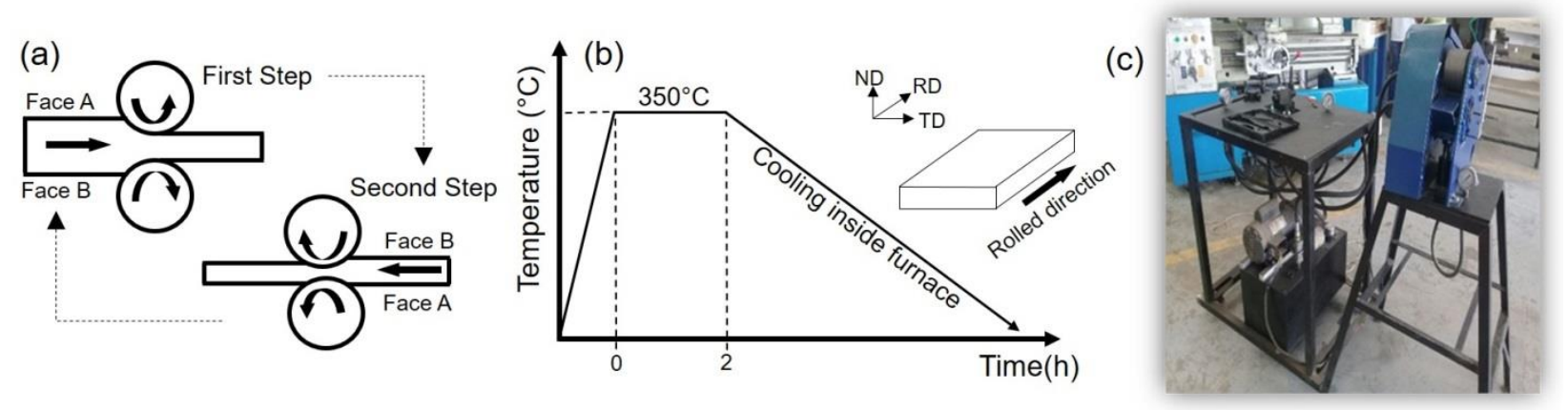

Figure 1. (a) Sketch of reverse cold rolling process. (b) Heat treatment and traceability directions (ND normal direction, RD rolled direction, TD transverse direction). (c) Rolling mill machine used

The goal of this work is to establish relationships among texture, mechanical properties and the microstructure changes during different stages of reverse cold rolling process applied on aluminium alloy AA1100-H14, trying to determine differences between measurements crystallographic and texture behaviour.

\section{METHODS AND MATERIALS}

\section{Materials and Processes}

Aluminium alloy sheets AA1100-H14 with $6 \mathrm{~mm}$ initial thickness and dimensions of $200 \mathrm{~mm} \times 100 \mathrm{~mm}$ were used. Chemical composition was carried out by optical emission spectrometry and results are shown in Table 2. Before rolling process, sheets were annealed at $350{ }^{\circ} \mathrm{C}$ for $2 \mathrm{~h}$, as shown in Figure $1 \mathrm{~b}$. Annealed sheets were then reverse cold rolled to reach thickness reductions of $16 \%, 33 \%, 50 \%$ and $67 \%$, respectively.

Table 2. Chemical composition for AA1100 aluminum alloy sheets (\%-wt.)

\begin{tabular}{ccccccccccc}
\hline $\mathbf{S i}$ & $\mathbf{F e}$ & $\mathbf{C u}$ & $\mathbf{M n}$ & $\mathbf{M g}$ & $\mathbf{C r}$ & $\mathbf{N i}$ & $\mathbf{Z n}$ & $\mathbf{T i}$ & Others & $\mathbf{A l}$ \\
\hline 0.053 & 0.295 & 0.007 & 0.027 & 0.002 & 0.004 & 0.009 & 0.010 & 0.019 & 0.044 & 99.53 \\
\hline
\end{tabular}


RCR process was developed in a calibrated rolling mill machine showed in Figure 1c. No lubrication was used, and the diameters of rollers used was $102 \mathrm{~mm}$. The samples were rotated $180^{\circ}$ regarding to rolling direction (RD) after each pass. Table 3 shows the parameters of applied RCR process, including the percentage of reduction and the values of L/h ratio, where L represents the contact length of the rollers with the sheet, and h represents the average value of the sheet thickness. Three samples were made for each parameter's combination [15].

Table 3. Reverse cold rolling parameters used

\begin{tabular}{ccccc}
\hline Code & $\begin{array}{c}\text { Number of } \\
\text { passes }\end{array}$ & Final thickness & $\begin{array}{c}\text { Accumulated reduction of area } \\
\text { mm }\end{array}$ & $\begin{array}{c}\text { Values for } \mathbf{L} / \mathbf{h} \\
\text { ratio }\end{array}$ \\
\hline L16 & 3 & 5.02 & 16.33 & $0.70-0.79$ \\
L33 & 5 & 4.02 & 33.00 & $0.78-1.10$ \\
L50 & 7 & 3.03 & 49.50 & $0.80-1.41$ \\
L67 & 10 & 2.03 & 66.16 & $0.78-2.05$ \\
\hline
\end{tabular}

\section{Microstructure Characterization}

Samples for optical and electron microscopy analysis were extracted from annealed state and from each deformation stage. These samples were cut aiming to show microstructural changes in the normal, rolling and traverse directions. The three different directions of same sample of each stage were mounted in polyester resin 856 using a relation of approximately 10:1 resin and catalyst, with a curing time of 4 hours at room temperature. Standard metallographic preparation was carried out using ASTM 240, 320, 400, 600, 1000 and 2000 mesh. A polishing was then carried out with a $3 \mu \mathrm{m}$ and $1 \mu \mathrm{m}$ diamond paste suspension on a Struers ${ }^{\circledR}$ DP-Floc cloth with rotation speed of $150 \mathrm{rpm}$, constantly cooled with water. The final polishing was carried out by using colloidal silica of $0.03 \mu \mathrm{m}$ in suspension for $5 \mathrm{~min}$. Hydrofluoric acid (HF) with a concentration of $1.0 \%$-vol. was used as chemical reagent, rubbing the sample with cotton moistened with the etchant for a time of 120 s. Samples were observed in an Olympus ${ }^{\circledR}$ Vanox AHMT3 reflected light optical microscope, with Image ${ }^{\circledR}$ Pro Plus image acquisition data software. Scanning electron microscopy analysis was developed in a FEG-SEM JEOL $®$ model JSM-7800F equipped with an XFLASH® detector for backscattered electrons (BSE), and the precipitations were identified with chemical microanalysis EDS by using a voltage of $20 \mathrm{kV}$ and a working distance of $10 \mathrm{~mm}$.

\section{Mechanical Properties}

Samples of tensile tests from annealed material and the different deformation stage conditions were extracted according to ASTM E8M standard. A Criterion ${ }^{\circledR}$ MTS universal testing machine with $300 \mathrm{kN}$ capacity of load cell, using a $25.4 \mathrm{~mm}$ MTS $®$ extensometer, and fitted with an MTS ${ }^{\circledR}$ test suite acquisition data software was used. The tests were carried out by using $1.8 \mathrm{~mm} / \mathrm{min}$ strain rate and $1 \mathrm{kN}$ preload. 3 replicated samples were tensile tested for each deformation stage. Vickers microhardness (HV) measurements were carried out on samples for all previously described conditions and directions (ND, RD and TD). An MVK®-H0 microdurometer was used applying a load of 100gf during 15 s, a 10 megapixels Clemex ${ }^{\circledR}$ PE camera, and a software Clemex ${ }^{\circledR}$ CMT were also used. Microhardness were randomly measured in 10 different locations for each sample.

\section{X-Ray Diffractometry Characterization}

Macrotexture analysis was carried out by using a PANalytical ${ }^{\circledR}$ X-ray diffractometer using the goniometer in reflection mode. $\mathrm{CuK} \alpha$ radiation was used, with an angular step of $5^{\circ}$, for 5 seconds, and $4 \mathrm{~kW}$ of energy radiation. Measurements of X-ray diffraction patterns were performed on normal section in all samples for the entire conditions. The data obtained were analysed in the X'Pert ${ }^{\circ}$ Texture software to obtain the pole figures of planes $\{111\},\{220\}$ and $\{311\}$ and the orientation distribution functions (ODF's).

\section{EBSD Measurement}

The microtexture analysis was made applying the EBSD technique using an Ametek $®$ EBSD-EDAX detector coupled in a scanning electron microscope Philips ${ }^{\circledR}$ model XL30 ESEM and processed with the OIM® Analysis software. Microtexture measurements were developed for the same condition of macrotexture measurements. Surface of samples were prepared by mechanical polishing, followed by an ionic polishing (Cross-section) during $10 \mathrm{~h}$. For EBSD measurements an acceleration voltage of $25 \mathrm{kV}$, a $1500 \mathrm{x}$ magnification and a step of $0.17 \mu \mathrm{m}$ were used. After analysis crystallographic orientation maps (IOM) and high-quality maps (IQ) were obtained. 


\section{RESULTS AND DISCUSSION}

\section{Microstructure of Annealed and Deformed States}

Figure 2 shows the microscopy analysis of microstructure in all examined directions for AA1100-H14 under annealed conditions. The microstructure observed in both RD and ND sections displayed equiaxed grains, while TD section exhibits elongated and narrow grains parallel to rolled direction. Observed microstructure indicates that during annealing process the material reaches a partial recrystallization state, which is produced due to previous strain level and applied time of heating treatment [2]. Some finely dispersed precipitates were observed in the Al-rich matrix. EDS analysis show that they are most likely $\mathrm{Al}_{3} \mathrm{Fe}$ particles, which can be occurring because of the relatively higher atomic fraction of Fe in comparison to $\mathrm{Mn}(0.6 \%$ and $0.05 \%)$, respectively [1].

Evolution of microstructure during different reverse cold rolling process (RCR) stages is shown in Figure 3. As the strain level increases on aluminium alloy, an increment of the amount of elongation and oriented grains into RD direction can be observed, while decreasing of grain width due to RCR process happens, as expected. When the maximum strain is applied (67\%), into resulting microstructure is not possible to distinguish grain boundaries inwardly and a banding substructure is developed. This banding structure (Figure 3d) can be attributed to the high deformation stress accumulated during different RCR process stages, which might affect the texture and mechanical properties of the material [16, 17].
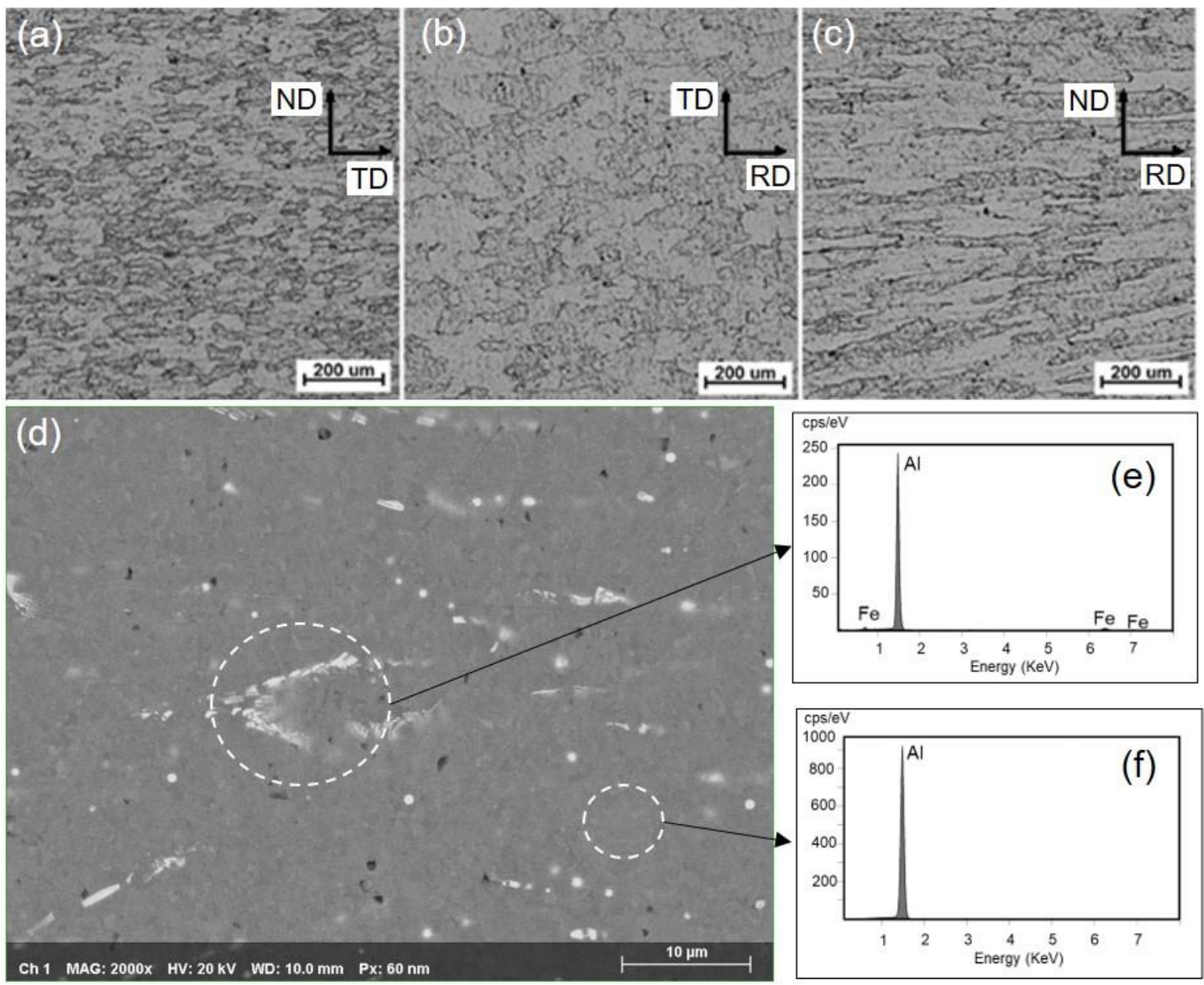

Figure 2. Microstructure of annealed AA1100-H14 to $350^{\circ} \mathrm{C}$. Reagent HF 1.0\%-v. Section: (a) RD, (b) ND, and (c) TD. Microanalysis of annealed material, (d) SEM-SE image. (e) $\mathrm{Al}_{3} \mathrm{Fe}$ precipitates, (f) chemical composition of matrix 

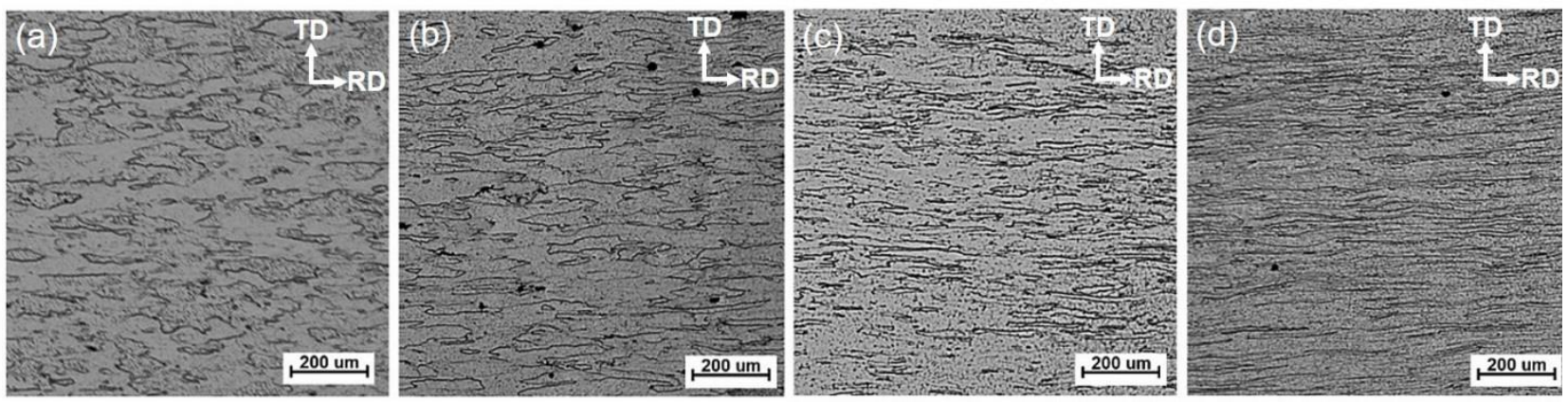

Figure 3. Optical microscopy images showing deformed microstructure across ND section: (a) 16\%, (b) 33\%, (c) 50\%, and (d) $67 \%$ of area reduction

\section{EBSD Analysis}

Image Quality (IQ) maps and orientation image maps (OIM) obtained from TD section for the conditions of: annealing and, thickness reduction of $33 \%$ and $67 \%$, are shown in Figure 4a. Coloured regions in OIM maps correspond to orientations of each grain, as indicated by inverse pole figure (IPF), while high angle boundary grains are indicated by black lines as displayed in Figure 4b. Microstructure observed on (0\%) annealed condition shows a mixture of equiaxed and elongated grains in the rolling direction, while a randomly texture with a lightly tendency to $\{111\}$ pole is displayed. For this same condition an equiaxed small grains (SG) of low angle grains boundary in OIM map were observed. Both the morphology and the significant misorientation of the grains confirm that aluminium alloy in annealed state was not fully recrystallized $[17,18]$.

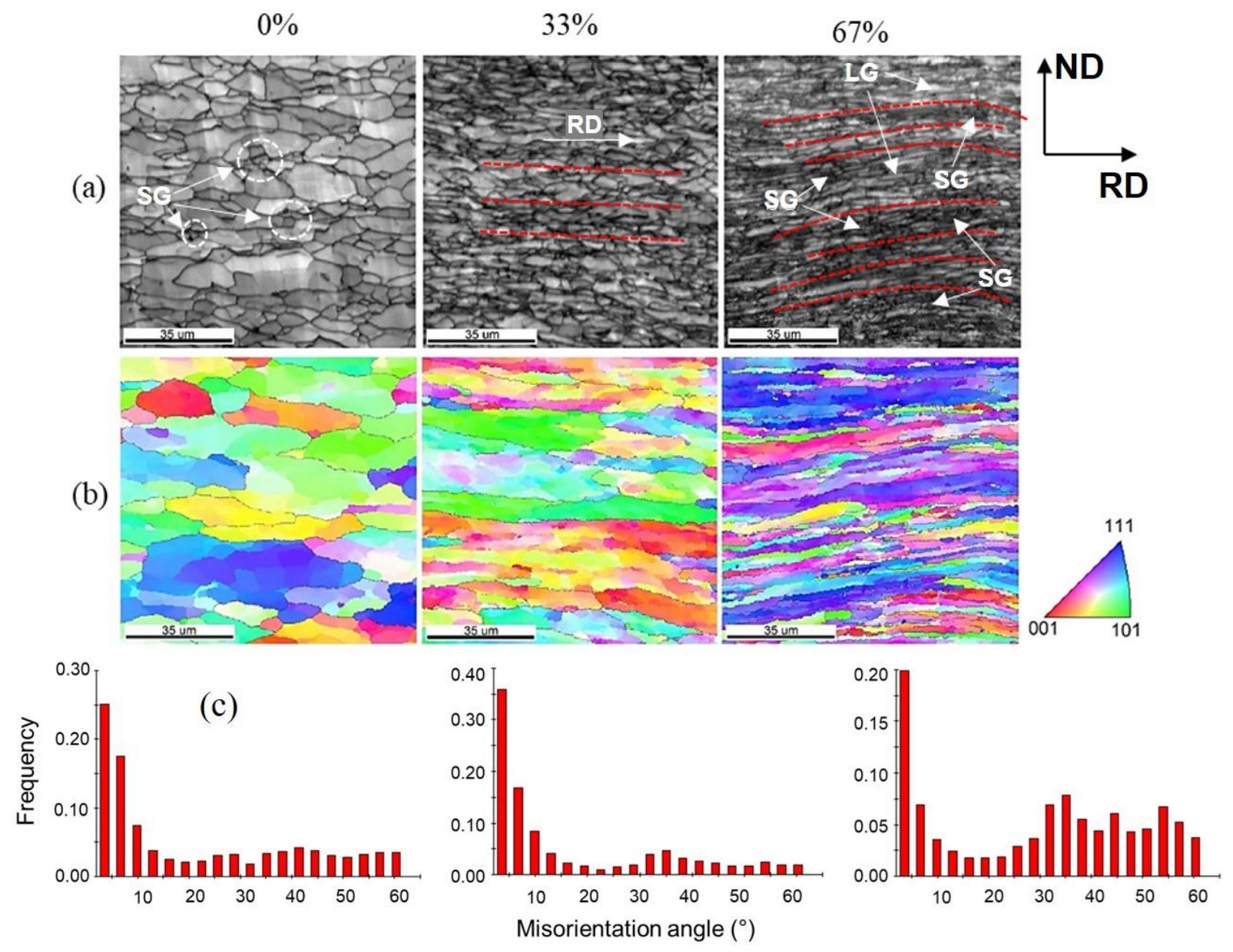

Figure 4. EBSD analysis results. (a) IQ Maps and (b) OIM Maps for aluminium alloy AA1100-H14 in annealed (0\%), $33 \%$, and 67\% of thickness reduction. (c) Diagram of misorientation angle distribution. EG: Enlarged grain; SG:

equiaxed small grain 
After 33\% thickness reduction, elongated and narrow grains on RD direction, showing high randomization of texture with lightly predomination of $\{001\}$ pole can be observed. The above mentioned indicates that a change in the orientation of the annealed grains towards a strain microstructure with different texture [18] has occurred. OIM results for $67 \%$ thickness reduction state show that deformation was not uniform, obtaining a slight deviation to RD direction and displaying a microstructure mostly of enlarged grains towards flow deformation direction with a few small grains, where $\{111\}$ pole predominates, again. It is possible that the deviation in the direction of rolling and the refinement of the grains are produced by the rotation of the sheet around RD [19]. Drastic changes in strain path could cause that shear stresses imposed on the contact surfaces are extended along the thickness of the sheet [20]. In the same way, these stresses can cause the rotation and subdivision of grains, which leads to refinement of grains for sufficient amounts of deformation [21].

Figure $4 \mathrm{c}$ shows diagrams of distribution of misorientation angle obtained by EBSD technique for samples in annealing, 33\%, and $67 \%$ thickness reduction states. From these results, it is possible to infer that if strain level and the number of passes (RCR cycles) increases, the elongated and refined grain with high angle grain boundaries increase, during RCR process. The refinement of the grain depends mainly on sliding and stacking of dislocations, reason why dislocation rearrangement during deformation produces many sub-grains with low angle grain boundaries (LAGB). LAGB in deformed grains increase during deformation, therefore those are transformed into high angle grain boundaries (HAGB), producing small equiaxed grains in the microstructure [22]. Conventional rolling comprises both compression and surface shear strain, as a result of friction between the rollers and the workpiece [23]. During RCR, the shear strain direction is rotated 180 degrees around the normal direction. Because of this direction reversal, the equivalent plastic strain across the workpiece is steeper in conventional steep rolling than the one found in RCR. This difference in plastic strain gradients leads to a reduced dislocation density in the RCR sample when compared to a conventional rolled sample [24]

\section{Texture Analysis by X-ray Diffraction}

ODF's results of AA1100-H14 aluminium alloy obtained by DRX and from perpendicular direction to ND section for: annealed and 50\%, and 67\% deformed samples are shown in Figure 5. ODF of annealed state exhibits that main texture component is R-cube with a maximum intensity of 246.17 in $\varphi 1=80^{\circ}, \Phi=0^{\circ}$ and $\varphi 2=60^{\circ}$. It has been found that the R-cube texture component for high purity aluminium alloys remains stable during the annealing at a temperature close to $350{ }^{\circ} \mathrm{C}$ [25-27]. ODF of samples with 50\% thickness reduction shows the following predominant texture components: $\{114\}<110>$ and $\{112\}<110>$ rotated at $20^{\circ}$ and $35^{\circ}$ from the R-cube component, with maximum intensity values of 29.04 and 13.35, respectively. ODF of samples with $67 \%$ thickness reduction show that intensity of R-cube components decreases, while $\{112\}<110>$ unstable component intensity increases. 
(a)

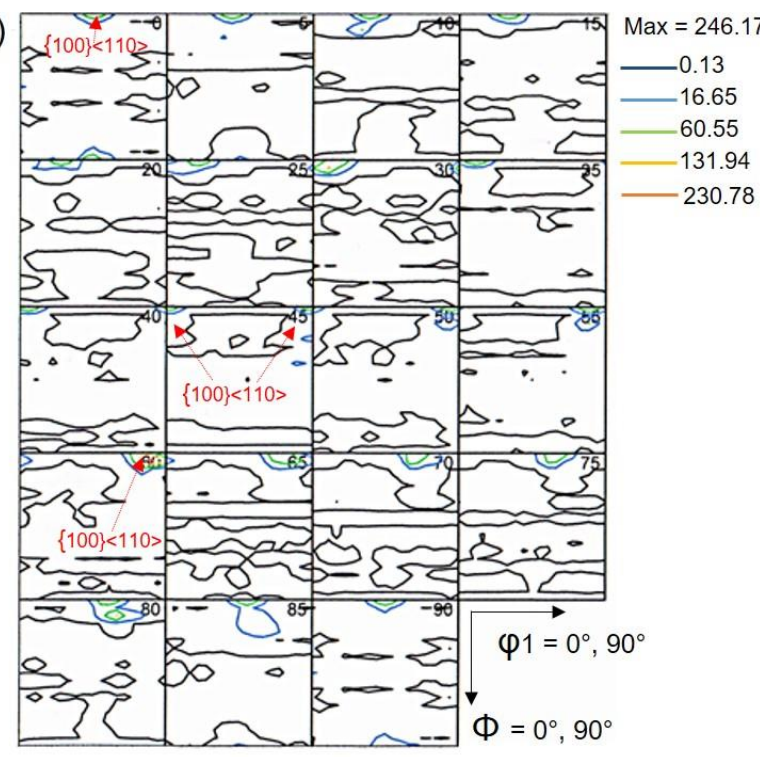

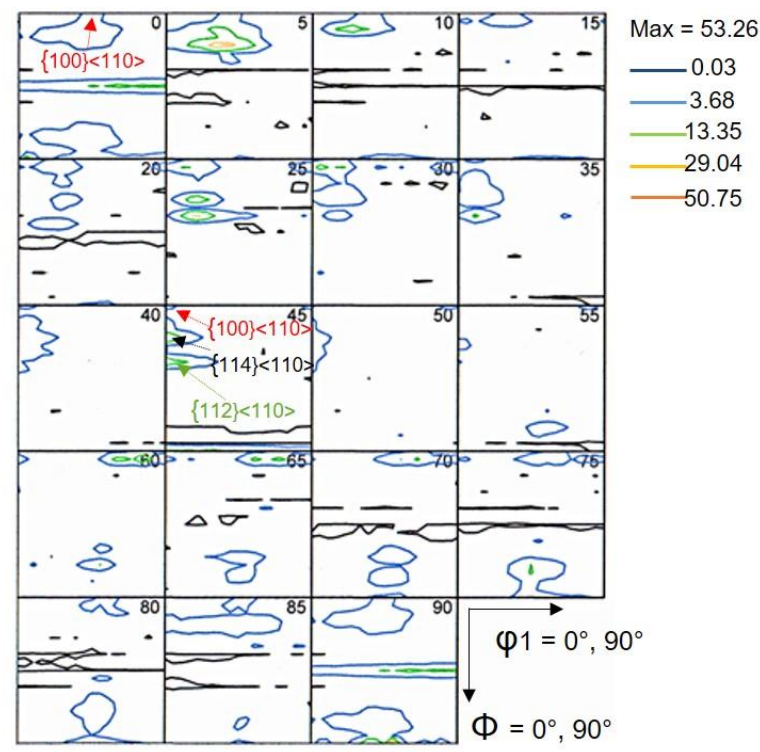

(c)

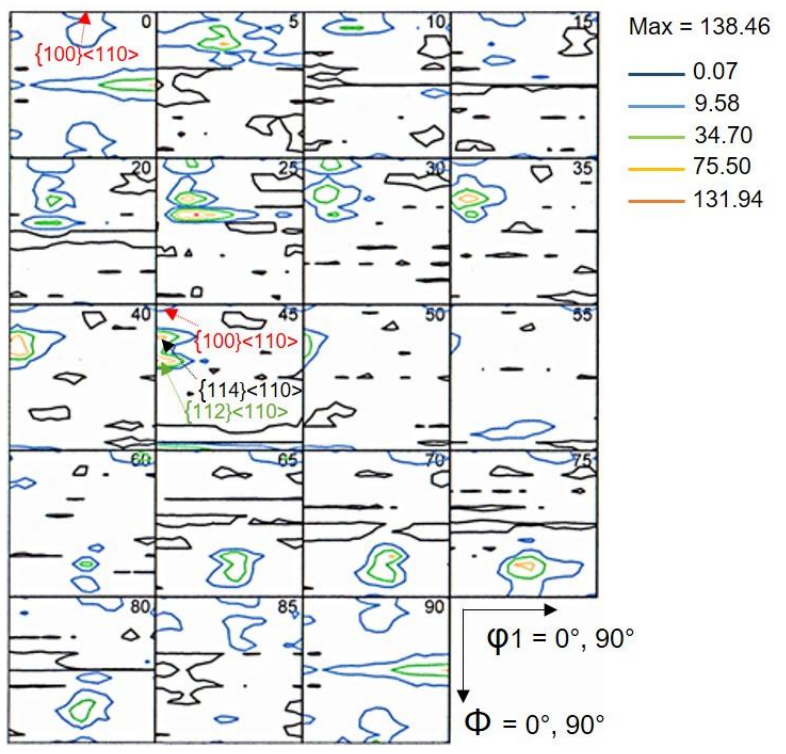

Figure 5. ODF results for AA1100-H14 aluminium alloy in states: (a) annealed, (b) 50\%, and (c) 67\% of thickness reduction

The presence of $\beta$-fiber was not observed in any stage of cold rolling. The non-formation of the $\beta$-fiber for an aluminium alloy of commercial purity can be discussed in terms of the parameters of the rolling process, such as the rollgap geometry, which depends on the ratio $\mathrm{L} / \mathrm{h}$ [27]. For values of $0.5<\mathrm{L} / \mathrm{h}<5$ the role-gap geometry does not affect the formation of shear textures [15]. In the present work, ratio values of $\mathrm{L} / \mathrm{h}$ were kept in this range for each pass during rolling (see Table 3). Therefore, the spacing between the rollers did not affect rolling texture components present in $\beta$ fiber.

It is well-known that shear stresses can develop shear textures during cold rolling of aluminium alloys [28]. However, changes in deformation path could cause that imposed shear stress on contact surfaces is extended along thickness, which could modify deformation substructure [20], [22], [25], [26]. These changes could limit the dislocations mobility and crystals rotation towards $\beta$-fiber, producing that components of lamination with Copper $(\mathrm{Cu}), \mathrm{S}$, and Brass $(\mathrm{Bs})$ textures are transformed in unstable components $\{112\}\langle 110\rangle,\{213\}\langle 031\rangle$ and $\{011\}\langle 111\rangle$ [27]. In the present work, the results show that for $67 \%$ reduction thickness, the effects of shear stress due to change of rolling direction is significant, generating a slight deviation related to rolling direction during deformation flow. These observations suggest that texture component $\{112\}<110>$ appears due to shear stress during deformation, being big enough to affect the development of rolling texture, decreasing $\beta$-fiber intensity, as it has been reported in the literature [21].

\section{Mechanical Properties}

Figure 6a shows the comparison among tensile test results for AA1100-H14 aluminium alloy in annealed state and different reduction thickness stages. It was observed that as the rolling cycles (i.e. hardening work) of RCR process 
increase, both ultimate strength $\left(S_{U}\right)$, and yield strength $\left(S_{Y}\right)$ increase while elongation decreases, as expected. Maximum values of yield strength and ultimate strength were $106 \mathrm{MPa}$ and $117 \mathrm{MPa}$, respectively for $67 \%$ thickness reduction. Conditions above-mentioned leads to achieve increments of $76 \%$ and $43 \%$, respectively, compared to the same values obtained for the annealed sample, as well as a $92 \%$ of ductility decrease, as shown in Figure $6 \mathrm{~b}$. The improvement of tensile strength is attributed to change in strain path during the reverse cold rolling, which increases the stored deformation energy (strain hardening), while decreases the grain size during process [21], [28], [29].

Vickers microhardness results display coherent behaviour to tensile strength results as shown in Figure 6c. The average hardness values show an increment for 39\% through $67 \%$ of thickness reduction regarding to annealing state. Longitudinal and transverse directions (RD and TD) showed higher values of hardness regarding to normal (ND) direction ( 5 to $10 \%$ the highest). Factors such as refinement of grain size and increasing of grain boundaries density influenced on raising the average hardness values during this process [21]. Microstructure and texture analysis showed refinement of grain and an increasing amount of high angle grain boundaries (HGBA), while thickness reduction was raised, which induced an increment of hardness and tensile strength by RCR process, as observed in others previous works [30, 31].
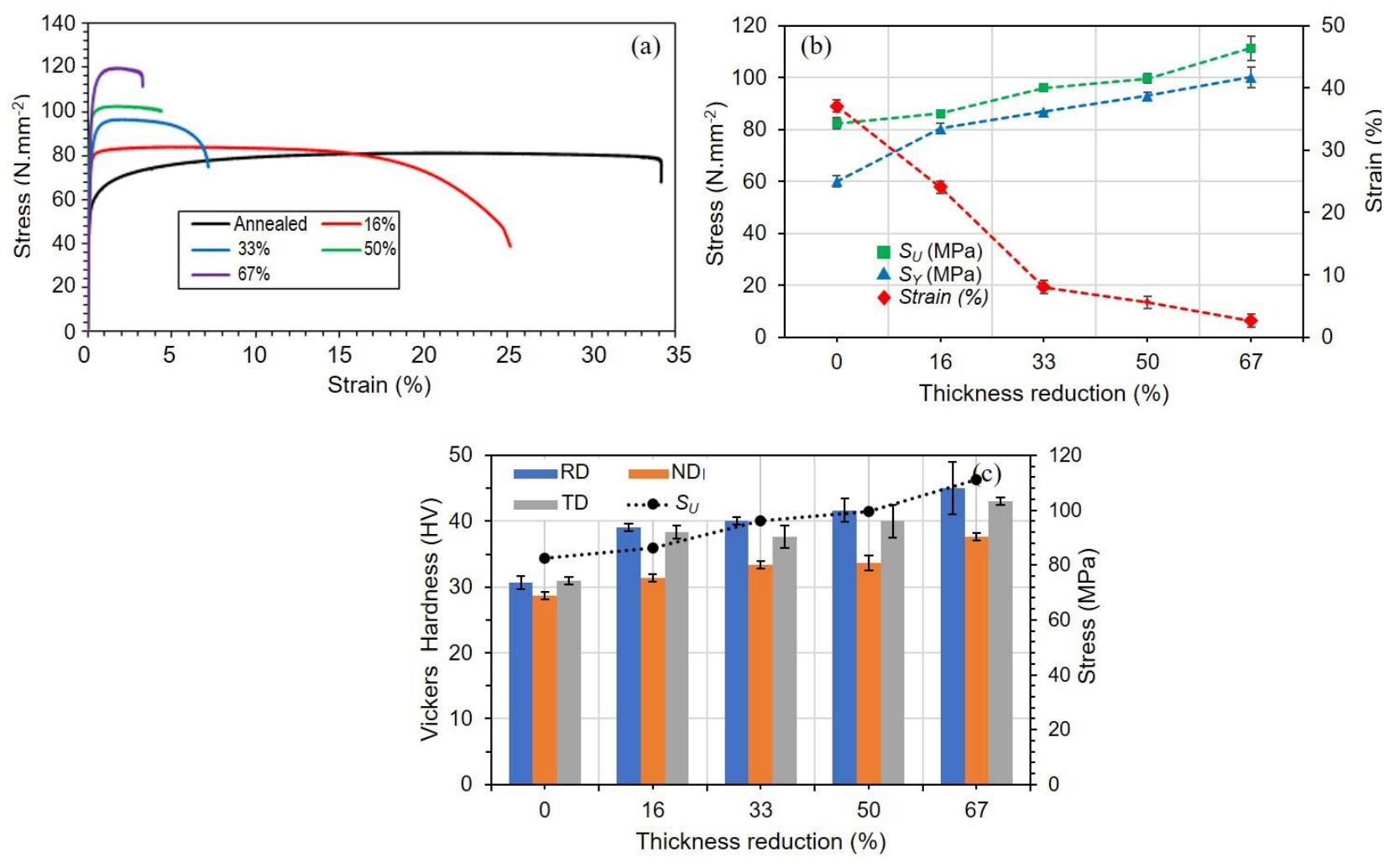

Figure 6. (a) Tensile test results, (b) $S_{U}, S_{Y}$, and strain, and (c) Vickers hardness in ND, RD and TD directions for different deformation stages. "O" state of area reduction corresponds to annealed stage

\section{CONCLUSIONS}

In this study, the effects of reverse cold rolling (RCR) on the microstructure, texture, and mechanical properties of AA1100-H14 aluminium alloy were investigated. The most important results obtained can be summarized as follows:

1. The RCR process produced a microstructure of deformed and refined grains with high angle of grain boundaries (HAGB) oriented into rolled direction (RD). This fact was attributed to rotations and alternations of the sheets on parallel and perpendicular directions to RD direction during processing.

2. OIM's of microstructure highly deformed (67\% thickness reduction) showed deformed and enlarged grains randomly distributed and with light tendency to $\{111\}$ pole, which was again attributed to the rotation and alternance of rolling direction of the sheet around RD during RCR process.

3. Maximum intensity of texture in the reverse cold rolling samples with $67 \%$ of thickness reduction was observed in the unstable component $\{112\}<110\rangle$, which was attributed to shear stress during deformation, affecting the development of lamination texture, decreasing $\beta$-fiber intensity.

4. Owing to microstructure, micro- and macrotexture changes in processed material, the mechanical properties (tensile strength and hardness) increased gradually when cycles of reverse cold rolling process also increased, increasing the stored deformation energy and decreasing grain size during process. Consequently, the maximum values of mechanical properties for $67 \%$ of thickness reduction were produced. 


\section{ACKNOWLEDGEMENTS}

The authors wish to thank to Universidad de Córdoba for the financial support that made possible the research internship for students Rivero and Pico. Special thanks to Universidad Autónoma de Coahuila in Monclova and the CINVESTAV in Saltillo for allowing the use of the facilities and experimental support.

\section{REFERENCES}

[1] B. B. Lindahl and M. Selleby, "The Al-Fe-Mn system revisited-An updated thermodynamic description using the most recent binaries," Calphad Comput. Coupling Phase Diagrams Thermochem., 2013, doi: 10.1016/j.calphad.2013.05.001.

[2] A. S. Khan and H. Liu, "Variable strain rate sensitivity in an aluminum alloy: Response and constitutive modeling," Int. J. Plast., 2012, doi: 10.1016/j.ijplas.2012.02.001.

[3] S. Naghdy, L. Kestens, S. Hertelé, and P. Verleysen, "Evolution of microstructure and texture in commercial pure aluminum subjected to high pressure torsion processing," Mater. Charact., 2016, doi: 10.1016/j.matchar.2016.09.012.

[4] S. Mohanty, S. P. Regalla, and Y. V. D. Rao, "Influence of process parameters on surface roughness and forming time of Al1100 sheet in incremental sheet metal forming," J. Mech. Eng. Sci., 2019, doi: 10.15282/jmes.13.2.2019.11.0408.

[5] L. H. An, Y. Cai, W. Liu, S. J. Yuan, S. Q. Zhu, and F. C. Meng, "Effect of pre-deformation on microstructure and mechanical properties of 2219 aluminum alloy sheet by thermomechanical treatment," Trans. Nonferrous Met. Soc. China (English Ed., 2012, doi: 10.1016/S1003-6326(12)61733-6.

[6] K. A. Zakaria, F. H. A. Suhadak, M. B. Ali, S. Abdullah, and M. J. Ghazali, "Influence of mechanical properties on load sequence effect and fatigue life of aluminium alloy," J. Mech. Eng. Sci., 2017, doi: 10.15282/jmes.11.1.2017.6.0227.

[7] L. Zhang et al., "Texture, microstructure and mechanical properties of 6111 aluminum alloy subject to rolling deformation," Mater. Res., 2017, doi: 10.1590/1980-5373-MR-2017-0549.

[8] S. Li, Q. Zhao, Z. Liu, and F. Li, "A review of texture evolution mechanisms during deformation by rolling in aluminum alloys," J. Mater. Eng. Perform., 2018, doi: 10.1007/s11665-018-3439-y.

[9] L. Y. Kou, W. Y. Zhao, X. Y. Tuo, G. Wang, and C. R. Sun, "Effect of stress triaxiality on fracture failure of 6061 aluminium alloy,” J. Mech. Eng. Sci., vol. 14, no. 2, pp. 6961-6970, 2020, doi: 10.15282/JMES.14.2.2020.33.0545.

[10] A. J. Schwartz, M. Kumar, B. L. Adams, and D. P. Field, Electron backscatter diffraction in materials science. 2009.

[11] S. Suwas and N. P. Gurao, "Crystallographic texture in materials," J. Indian Inst. Sci., 2008.

[12] L. A. I. Kestens and H. Pirgazi, "Texture formation in metal alloys with cubic crystal structures," Materials Science and Technology (United Kingdom). 2016, doi: 10.1080/02670836.2016.1231746.

[13] X. Wang et al., "The dependence of microstructure, texture evolution and mechanical properties of Al-Mg-Si-Cu alloy sheet on final cold rolling deformation," J. Alloys Compd., 2016, doi: 10.1016/j.jallcom.2015.10.070.

[14] J. Sidor, R. H. Petrov, and L. Kestens, "Texture control in aluminum sheets by conventional and asymmetric rolling," in Comprehensive Materials Processing, 2014.

[15] O. V. Mishin, B. Bay, and D. Juul Jensen, "Through-thickness texture gradients in cold-rolled aluminum," Metall. Mater. Trans. A Phys. Metall. Mater. Sci., 2000, doi: 10.1007/s11661-000-0175-2.

[16] S. Y. Paredes-Dugarte and B. Hidalgo-Prada, "Micromecanismo de deformación durante la laminación en frio de la aleación comercial de aluminio 3003," Supl. la Rev. Latinoam. Metal. y Mater. S, vol. 1, pp. 775-781, 2009.

[17] W. Wang, A. L. Helbert, T. Baudin, F. Brisset, and R. Penelle, "Reinforcement of the cube texture during recrystallization of a 1050 aluminum alloy partially recrystallized and $10 \%$ cold-rolled," Mater. Charact., 2012, doi: 10.1016/j.matchar.2011.11.008.

[18] S. Li, N. Qin, J. Liu, and X. Zhang, "Microstructure, texture and mechanical properties of AA1060 aluminum plate processed by snake rolling," Mater. Des., 2016, doi: 10.1016/j.matdes.2015.11.054.

[19] M. Naseri, M. Reihanian, and E. Borhani, "Effect of strain path on microstructure, deformation texture and mechanical properties of nano/ultrafine grained AA1050 processed by accumulative roll bonding (ARB),” Mater. Sci. Eng. A, 2016, doi: 10.1016/j.msea.2016.07.031.

[20] N. P. Gurao and S. Suwas, "Generalized scaling of misorientation angle distributions at meso-scale in deformed materials," Sci. Rep., 2014, doi: 10.1038/srep05641.

[21] F. Goli and R. Jamaati, "Effect of strain path during cold rolling on the microstructure, texture, and mechanical properties of AA2024 aluminum alloy,” Mater. Res. Express, 2019, doi: 10.1088/2053-1591/ab0a1f.

[22] P. P. Bhattacharjee, S. Saha, and J. R. Gatti, "Effect of change in strain path during cold rolling on the evolution of microstructure and texture in Al and Al-2.5\%Mg," J. Mater. Eng. Perform., 2014, doi: 10.1007/s11665-013-0793-7.

[23] G. E. Dieter, Mechanical metallurgy. 2011.

[24] B. Koohbor, "On the influence of rolling path change on static recrystallization behavior of commercial purity aluminum," Int. J. Mater. Form., 2014, doi: 10.1007/s12289-012-1113-8.

[25] H. Yuan, J. Li, D. Cai, Q. Yang, and W. Liu, "Quantitative analysis of texture evolution of direct chill cast and continuous cast AA 1100 aluminum alloys during cold rolling,” 2007, doi: 10.2320/matertrans.MRA2007023. 
[26] F. J. P. Simões, R. J. A. de Sousa, J. J. A. Grácio, F. Barlat, and J. W. Yoon, "Effect of asymmetrical rolling and annealing on the mechanical response of an AA1050-O sheet," Int. J. Mater. Form., 2009, doi: 10.1007/s12289-009-0625-3.

[27] C. Mondal, A. C. Umamaheshwer Rao, G. R. N. Tagore, and A. K. Singh, "Effect of roll diameter and modes of rolling on evolution of texture in high purity aluminum," 2012, doi: 10.4028/www.scientific.net/MSF.702-703.987.

[28] L. Zhen, J. Chen, S. Yang, W. Shao, and S. Dai, "Development of microstructures and texture during cold rolling in AA 7055 aluminum alloy," Mater. Sci. Eng. A, 2009, doi: 10.1016/j.msea.2008.10.055.

[29] D. Peláez, C. Isaza, J. M. Meza, P. Fernández-Morales, W. Z. Misiolek, and E. Mendoza, "Mechanical and microstructural evolution of Mg AZ31 alloy using ECASD process,” J. Mater. Res. Technol., 2015, doi: 10.1016/j.jmrt.2015.04.003.

[30] J. K. Lee and D. N. Lee, "Shear texture development and grain refinement in asymmetrically rolled aluminum alloy sheets by varied reduction per pass," 2002, doi: 10.4028/www.scientific.net/msf.408-412.1419.

[31] J. K. Lee and D. N. Lee, "Texture evolution and grain refinement in AA1050 aluminum alloy sheets asymmetrically rolled with varied shear directions," Key Eng. Mater., 2007, doi: 10.4028/www.scientific.net/kem.340-341.619. 